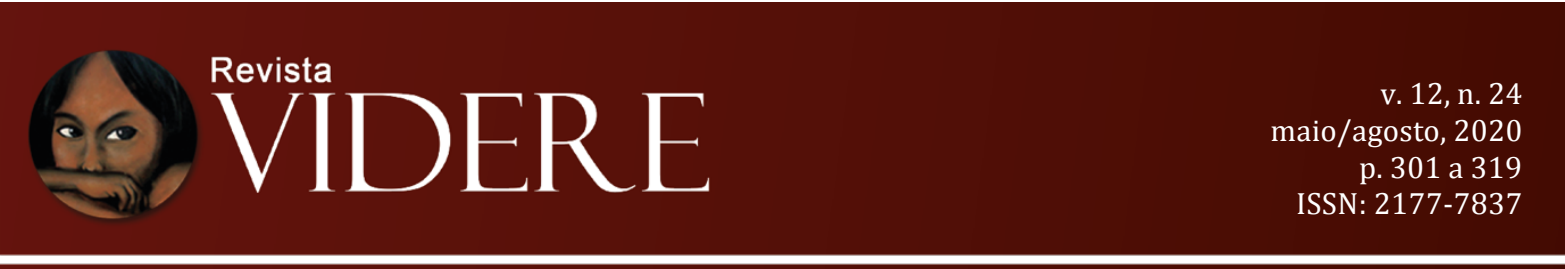

\title{
AS CONDENAÇÕES DO ESTADO BRASILEIRO PELA CORTE INTERAMERICANA DE DIREITOS HUMANOS E SUAS REPERCUSSÕES NA ORDEM JURÍDICA INTERNA
}

\section{THE CONVICTIONS OF THE BRAZILIAN STATE FOR THE INTER- AMERICAN COURT OF HUMAN RIGHTS AND THEIR REPERCUSSIONS IN THE INTERNAL LEGAL ORDER}

\author{
Tássia A. Gervasoni \\ Doutora em Direito - UNISINOS/Universidad de \\ Sevill, Brasil. Professora do Programa de Pós- \\ Graduação Stricto Sensu, na Faculdade Meridional \\ (IMED), Brasil. \\ E-mail: tassiagervasoni@gmail.com \\ OrcID: http://orcid.org/0000-0002-8774-5421
}

\author{
Tamiris Alessandra Gervasoni \\ Mestra em Direito (UNISC), Brasil \\ E-mail: tamirisgervasoni@gmail.com \\ OrcID: http://orcid.org/0000-0003-2142-995X
}

RESUMO: Este trabalho abordará o sistema interamericano de proteção aos direitos humanos e as condenações sofridas pelo Estado brasileiro, visando responder ao seguinte problema: quais as repercussões das condenações internacionais por violação de direitos humanos sofridas pelo Brasil no ordenamento jurídico interno? Tem-se por objetivo analisar o contexto das sentenças condenatórias e, a partir das determinações da Corte Interamericana, avaliar as medidas legislativas e políticas públicas desenvolvidas em razão da incorporação de tais decisões ao ordenamento jurídico interno. Emprega-se uma metodologia de abordagem dedutiva, métodos de procedimento monográfico e histórico e técnica de pesquisa por documentação indireta.

PALAVRAS-CHAVE: Corte Interamericana; Direitos Humanos; Internacionalização.

ABSTRACT: This paper will approach the Inter-American system for protection of human rights and the convictions suffered by the Brazilian State, in order to answer the following problem: what are the repercussions of international condemnations for human rights violations suffered by Brazil in the domestic legal system? Its purpose is to analyze the context of convictions and, based on the determinations of the Inter-American Court, to evaluate the legislative measures and public policies developed due to the incorporation of such decisions into the domestic legal system. It is used a methodology of deductive approach, methods of monographic and historical procedure and research technique by indirect documentation.

KEYWORDS: Inter-American Court; Human rights; Internationalization. 


\section{Introdução}

O presente trabalho abordará o sistema interamericano de proteção aos direitos humanos e as condenações sofridas pelo Estado brasileiro por este sistema regional, visando responder ao seguinte problema: quais as repercussões das condenações internacionais por violação de direitos humanos sofridas pelo Brasil no ordenamento jurídico interno?

Objetivando responder à questão proposta, será analisado o contexto das sentenças condenatórias e, a partir das determinações da Corte Interamericana de Direitos Humanos, serão avaliadas as medidas legislativas e políticas públicas desenvolvidas em razão da incorporação de tais decisões ao ordenamento jurídico interno.

Para tanto, será empregada uma metodologia de abordagem dedutiva, partindo-se de proposições gerais acerca dos direitos humanos e do funcionamento do sistema regional de proteção para, ao final, especificar a análise com foco nas decisões e seus efeitos concretos. Os métodos de procedimento serão o monográfico (pelo recorte específico com que se pretende desenvolver o estudo) e o histórico (dada a necessária retomada histórica que precisará ser conduzida para a compreensão de diversas categorias da pesquisa). Como técnica de pesquisa, valer-se-á da documentação indireta, mediante pesquisa bibliográfica e análise das decisões.

O texto será divido em três momentos: (i) incialmente, buscar-se-á uma aproximação conceitual sobre direitos humanos e seus sistemas de proteção; (ii) em seguida, far-se-á um detalhamento acerca do sistema interamericano, objeto específico da pesquisa; (iii) e, finalmente, proceder-se-á ao estudo das condenações sofridas pelo Brasil e os modos de incorporação das determinações sentenciadas pela Corte no ordenamento jurídico interno.

\section{Direitos humanos na perspectiva da teoria crítica e a necessidade de sistemas regionais de proteção}

Os direitos humanos não resultam, tampouco restringem-se às abstrações textuais dos conceitos jurídicos expressos em diversos documentos internacionais. Tais direitos são atrelados, em geral, a um discurso jurídico produzido institucionalmente na perspectiva ocidental, criando-se daí o que Gallardo denomina de abismo entre o que se diz e o que se faz sobre direitos humanos (2010, p. 55), já que a presença do conceito no âmbito jurídico, em 
constituições e códigos, não tem garantido a sua concretização (GALLARDO, 2014, p. 30), mas ao contrário, tem-se estabelecido uma cisão entre teoria e prática.

Uma perspectiva crítica aos direitos humanos faz-se necessária diante do fato de que a utilização de um conceito sobre o que eles são e representam pode ter íntima relação com determinados conteúdos eminentemente ideológicos ${ }^{139}$ (HERRERA FLORES, 2009, p. 9), podendo, portanto, serem utilizados como meio de opressão e dominação. Essa preocupação faz-se pertinente se analisado o próprio contexto seminal destes direitos no período da Revolução Francesa, quando estavam unicamente alinhados aos interesses (ocidentais burgueses) prevalentes da época, do homem branco, heterossexual, cristão e proprietário.

"Desalinhar" os direitos humanos do discurso hegemônico que se enquadram, por vezes, aos textos jurídicos impregnados pela lógica moderna universalista e positivista dos direitos humanos implica em uma (re)interpretação destes direitos não como meras regras e garantias jurídicas, mas enquanto produtos históricos e socioculturais, em constante desconstrução diante das intensas dinâmicas e demandas sociais. Tais direitos representam, também, produções simbólicas, influenciadas por grupos específicos como forma de ação e reação diante das distintas realidades políticas, sociais e culturais nas quais estão inseridos; assim, representam notadamente pautas de emancipação e enfrentamento das forças hegemônicas (HERRERA FLORES, 2009, p. 40).

Esse caráter emancipador e contra-hegemônico dos direitos humanos é imprescindível diante das inúmeras violações diárias que ocorrem destes direitos, muitas vezes pela apropriação do seu discurso institucional, pois, delimitado então, dentro de um conceito jurídico, não alcança a diversidade e a complexidade do cotidiano. Logo, aqueles que não se enquadram nesse discurso, necessitam dessa perspectiva crítica dos direitos humanos, contestando a sua premissa de universalidade que se mostra ilusória (CHAUÍ, 2012, p. 109). Será, portanto, na perspectiva crítica sobre os direitos humanos que encontrarão apoio, visto que esta propõe uma concepção calcada na "constante criação e recriação à medida que o sujeito atua no processo de construção social da realidade" (PRONER, 2002, p. 41).

Assim, inserindo-se no campo dos direitos humanos aquilo que é considerado oposto, antagônico e subversivo, mas que é integrante do seu processo constante de (des)construção, e que foi afastado pela percepção eurocêntrica moderna, retirando aquilo que

\footnotetext{
${ }^{139}$ Sobre o termo ideologia, tem-se que: "Ideologia é assim a representação de uma sociedade faz de si mesma e do mundo que a envolver em dado momento histórico. Ela é inseparável da sociedade, que a constrói, e da história, que é por assim dizer o meio onde ocorre a ideologia. Há, portanto, uma relação de imanência entre a ideologia e sociedade em si considerada em um momento histórico determinado" (COELHO, 2003, p. 134).
} 
não convinha do discurso sobre direito humanos, é que seria possível consolidá-los de modo plural e acolhedor, não havendo padrão, incluindo-se todos e, por conseguinte, aqueles que precisam resistir às violências.

\begin{abstract}
A hegemonia dos direitos humanos como linguagem de dignidade humana é hoje incontestável. No entanto, esta hegemonia convive com uma realidade perturbadora. A grande maioria da população mundial não é sujeito de direitos humanos. É hoje objeto de discursos de direitos humanos. Deve pois começar por perguntar-se se os direitos humanos servem eficazmente a luta dos excluídos, dos explorados e dos discriminados ou se, pelo contrário, a tornam mais difícil. Por outras palavras, será a hegemonia de que goza hoje o discurso dos direitos humanos o resultado de uma vitória histórica ou, pelo contrário, de uma derrota história? (SANTOS, 2013, p.42).
\end{abstract}

Vê-se que, diante de tais exclusões dentro do próprio discurso sobre os direitos humanos universais, enquanto discurso hegemônico que não reconhece a todos como sujeitos de direito, também a sua aplicação não é universal. Em termos históricos, as preocupações voltadas a estes direitos, desde o seu reconhecimento em caráter universal até a sua efetiva garantia, intensificaram-se após o término da Segunda Guerra Mundial, justamente em consequência das atrocidades ocorridas em tal momento. A comunidade internacional, por conseguinte, congrega esforços para que a proteção dos direitos humanos não ficasse adstrita à atuação dos Estados, criando-se sistemas internacionais de proteção aos direitos humanos, os quais, aliás, poderão responsabilizar os próprios Estados que violarem estes direitos.

A proteção dos direitos humanos em âmbito internacional consolida-se em 1948, com a Declaração Universal dos Direitos Humanos. Aliando-se a este documento, somam-se o Pacto Internacional de Direitos Civis e Políticos, de 1966, e o Pacto Internacional de Direitos Econômicos, Sociais e Culturais, do ano de 1966. Estes documentos internacionais constituem o sistema de proteção de direitos humanos da Organização das Nações Unidas (ONU), reconhecido como sistema universal. Este reconhecimento dá-se em virtude do caráter de vetor interpretativo e fonte direta dos seus documentos constituintes (PRONER, 2002, p. 29) para o reconhecimento de direitos nos demais sistemas de proteção, denominados de sistemas regionais de proteção aos direitos humanos.

Atualmente, são observados no plano internacional quatro sistemas regionais de proteção aos direitos humanos: europeu (organizado pelo Conselho da Europa), (inter)americano (organizado pela Organização dos Estados Americanos), africano (organizado pela União Africana) e árabe (organizado pela Liga dos Estados Árabes). Entretanto, no que tange ao sistema árabe - ainda em desenvolvimento -, o seu 
reconhecimento não é pacífico, tanto na doutrina especializada, quanto na comunidade internacional. Argumenta-se a inexistência de mecanismos efetivos para o processamento de petições sobre violação de direitos, como uma comissão de investigação e/ou uma corte para julgamento. Todavia, considerando que a ideia de direitos humanos está, historicamente, atrelada à cultura ocidental e a sua concepção de dignidade humana, reconhecer a possibilidade de coexistência de concepções distintas ${ }^{140}$, como, por exemplo, as existentes nas sociedades islâmicas ${ }^{141}$ - que consideram a palavra do profeta e o alcorão nas suas compreensões $^{142}$-, pode representar incentivo para o não reconhecimento do sistema árabe de proteção aos direitos humanos pela parte ocidental do globo.

Estes sistemas regionais de proteção aos direitos humanos garantem que as especificidades de cada uma das suas localidades e países componentes sejam observadas com maior atenção em comparação com a universalidade do sistema global da ONU. Além disso, em virtude desta proximidade, a possibilidade de concordância entre o que preveem os documentos internacionais de cada sistema regional e a ordem jurídica interna dos países é maior, o que influencia na execução das decisões dos sistemas regionais pelos Estados devidamente responsabilizados por violação de direitos humanos.

\section{O Sistema Interamericano de Proteção aos Direitos Humanos: das origens ao}

\section{funcionamento}

Observa-se que apesar da existência de distintos sistemas regionais de proteção aos direitos humanos, em consequência da própria limitação da pesquisa proposta, a análise e estudo centrar-se-ão exclusivamente no sistema interamericano, com enfoque na sua relação com o Brasil e respectivas violações de direitos humanos pelo Estado brasileiro.

O Sistema Interamericano tem inspiração e influência no sistema global das Organizações das Nações Unidas (ONU), reconhecendo os mesmos direitos deste sistema,

\footnotetext{
140 "Todas as culturas possuem diferentes concepções de dignidade humana, mas nem todas as concebem sob a forma de direitos humanos. O que há de ser feito é encontrar os denominadores comuns e diferenças entre direitos humanos produzidos no Ocidente e os equivalentes isomórficos que possuem um estágio similar ou nível de importância equivalente nas culturas que os defendem" (SÁNCHEZ RUBIO, 2014, p. 51).

141 "No paralelo entre as sociedades islâmicas e ocidentais as diferenças culturais e de valores destacam-se e referendam a impossibilidade de considerar os direitos humanos universais, pois os direitos humanos muçulmanos e ocidentais são incompatíveis quanto à aplicabilidade de suas normas, tendo em vista que os Estados ocidentais orientam-se pelo princípio da laicidade e os países islâmicos têm como razão do Estado o código religioso, onde também assentam a moral e a ética que baseiam suas leis" (OLIVEIRA, 2016, p. 41).

142 "Essas contradições se dão porque os tratados internacionais islâmicos ao tutelarem os direitos humanos, consideram as leis corânicas e a palavra do profeta como a base da legislação islâmica, o que causa polêmica entre as secções islâmicas e, sobretudo, em relação aos direitos humanos construídos no Ocidente" (OLIVEIRA, 2016, p. 42).
} 
ressalvando-se, contudo, que a concepção de direitos humanos de ambos os sistemas internacionais não pode dar-se de modo estático, com olhar fixo apenas para os documentos oficiais que lhes regem. Apoiar-se eternamente na existência de um conceito universal e internacional dos direitos humanos corresponderia propriamente a "ignorar o momento histórico de surgimento da Declaração Universal, momento tumultuado pela violência da Segunda Guerra e pelos profundos conflitos ideológicos das grandes potências" (PRONER, 2002, p. 42).

Dessa forma, adverte-se que, apesar da importância desses sistemas de proteção aos direitos humanos, eles, por si só, não resolvem todos os problemas existentes acerca das violações de direitos humanos. A leitura sobre tais mecanismos deve ser relacional e crítica, voltada para a possibilidade de união com outras alternativas e instrumentos de garantia e proteção aos direitos humanos, estatais e não-estatais.

No que tange ao histórico do Sistema Interamericano, podem ser rememorados os objetivos de Simon Bolívar de unificar a América Latina em uma República, expostos no Congresso do Panamá em 1826. Tal intuito não logrou êxito à época, todavia, congressos e reuniões que envolviam essa temática continuaram ocorrendo desde a formação da União Internacional das Repúblicas Americanas em 1880. As reuniões abordavam assuntos de interesse internacional dos países integrantes, como paz, segurança, comércio internacional, direitos das mulheres, nacionalidade, crimes de guerra, asilo, condições de trabalho, entre outros. Nesse compasso, na nona Conferência Interamericana, ocorrida em Bogotá, de 1948, adotou-se a Carta da Organização dos Estados Americanos, juntamente com a Declaração Americana dos Direitos e Deveres do Homem. A Carta da OEA destaca sua atenção para assuntos como desenvolvimento econômico e social dos países e paz duradoura, enquanto que a Declaração Americana preocupa-se em definir quais direitos deverão ser observados e garantidos. No ano de 1959, na Quinta Reunião de Consultas dos Ministros de Relações Exteriores, decidiu-se que o Conselho Interamericano de Juristas ficaria encarregado de elaborar um projeto de Convenção sobre Direitos Humanos. Na semana em que ocorreu referida reunião, foi criada a Comissão Interamericana de Direitos Humanos, tendo a atribuição de promover a observação dos direitos humanos pelos Estados integrantes da OEA. Assim, em 1960, aprovou-se o estatuto da CIDH, determinando-a "como entidade autônoma daquela organização, de caráter não convencional, cujo mandato se limitava estritamente à promoção do respeito aos direitos humanos consagrados na Declaração Americana" (PRONER, 2002, p. 98). 
Este estatuto da CIDH foi alterado algumas vezes, ocorrendo a primeira modificação cinco anos após a sua constituição originária, na Segunda Conferência Interamericana Extraordinária, no Rio do Janeiro. Transformou-se aí a Comissão Interamericana de Direitos Humanos em efetivo órgão de controle. Diante disso, a Comissão foi autorizada a receber e examinar petições individuais sobre possíveis violações de direitos humanos por parte dos Estados membros, podendo solicitá-los informações (OEA, 1969) para averiguar a veracidade das denúncias, bem como formular respectivas recomendações de acordo com suas verificações, todavia, sublinha-se que o status de resolução mantinha sua base jurídica muito frágil. Mais tarde, no ano de 1967, com o Protocolo de Buenos Aires, algumas modificações foram inseridas na própria Carta da OEA, sendo a Comissão incorporada à estrutura permanente da Organização, redefinindo as suas funções para além de um órgão consultivo, mas promotor e defensor dos direitos humanos. Ademais, a partir de então, para que esta Comissão possa ser extinta, será necessário que alterações sejam realizadas na própria Carta da OEA, tornando, assim, sua base jurídica mais sólida.

Apesar dessas transformações, a mais significativa delas realiza-se no ano de 1969, com a Convenção Americana de Direitos Humanos, célebre Pacto de São José da Costa Rica, que entra em vigor no ano de 1978. Diante das alterações pronunciadas e estabelecidas com a Convenção Americana, o sistema de proteção aos direitos humanos tem seu caráter meramente declaratório transformado, conferindo-lhe força jurídica para a observação das disposições normativas. Para além do respeito e observância aos direitos humanos previstos na Convenção, os Estados devem, a partir deste momento, adotar medidas internas para tornálos efetivos. Ainda, a Convenção redefine e reconfigura os mecanismos do sistema de proteção, que passa a ser bifásico, pois, além da Comissão, cria-se a Corte Interamericana de Direitos Humanos.

O Sistema Interamericano de proteção aos direitos humanos, composto pela Comissão e pela Corte, tem como uma de suas funções precípuas supervisionar se os Estados membros observam, respeitam e promovem as disposições dos tratados interamericanos sobre direitos humanos, bem como averiguar se existem medidas adotadas para torná-los efetivos $^{143}$.

\footnotetext{
43 Além da Convenção Americana de Direitos Humanos, da Carta da OEA e da Carta Democrática Interamericana, os seguintes documentos integram o sistema de proteção aos direitos humanos: Convenção Interamericana para Prevenir e Punir a Tortura (1985), Protocolo de San Salvador - Protocolo Adicional à Convenção Americana sobre Direitos Humanos em matéria de Direitos Econômicos, Sociais e Culturais (1988), Protocolo à Convenção Americana sobre Direitos Humanos referente à Abolição da Pena de Morte (1991), Convenção de Belém do Pará - Convenção Interamericana para Prevenir, Punir e Erradicar a Violência contra a Mulher (1994), Convenção Interamericana sobre o Desaparecimento de Pessoas (1994), Convenção
} 
Em relação à observância dos documentos internacionais que compõem esse sistema pelos Estados membros, a Comissão Interamericana de Direitos Humanos é o órgão encarregado de efetuar a devida averiguação, não obstante haja ainda sua função de órgão consultivo para os Estados membros conforme previsão do artigo 43 da Convenção (OEA, 1969). Caso algum Estado integrante da OEA e signatário desses tratados esteja violando direitos humanos previstos nestes documentos, qualquer indivíduo, grupo de pessoas ou entidade não-governamental poderá efetuar denúncia ou queixa à Comissão (OEA, 1969), que se encarregará de analisar a situação ${ }^{144}$. Após o encaminhamento deste relatório ao Estado denunciado, há um prazo de três meses para que cumpra as recomendações que lhe foram dirigidas. Se dentro desse prazo o Estado não observar o relatório, não adotando medidas cabíveis para cumpri-lo, a Comissão estabelecerá novo prazo para tanto. Transcorrido esse novo prazo e não tendo o Estado cumprido o recomendado, o relatório, que era confidencial, tornar-se-á público e integrará o relatório anual apresentado à Assembleia Geral da OEA. Outra possibilidade, nesse caso, será remeter o caso à Corte Interamericana da Justiça.

Todavia, só há essa possibilidade em relação aos Estados que ratificaram a Convenção Americana e reconheceram a competência desta Corte ${ }^{145}$, exceto nas situações específicas em que o Estado aceite expressamente esta competência para caso determinado. A Corte, diversamente da Comissão, além do caráter consultivo, possui status jurisdicional, não havendo recurso de apelação de suas decisões, que correspondem a uma condenação internacional por violação de direitos humanos. É um órgão autônomo, sediado em São José, na Costa Rica. Composta por sete juízes, cabe-lhe a função de interpretar e aplicar a Convenção Americana de Direitos Humanos, bem como os demais tratados integrantes do

Interamericana para a Eliminação de Todas as Formas de Discriminação contra as Pessoas Portadoras de Deficiência (1999), Convenção Interamericana contra o Racismo, a Discriminação Racial e Formas Correlatas de Intolerância (2013), Convenção Interamericana contra Toda Forma de Discriminação e Intolerância (2013), Declaração de Princípios sobre Liberdade Expressão (2000) e Princípios e Boas Práticas para a Proteção das Pessoas Privadas de Liberdade nas Américas (2008) (OEA, 2016).

${ }^{144}$ A Comissão é composta por sete membros independentes, especialistas em direitos humanos e, para que possam analisar as denúncias de modo imparcial, não representam nenhum Estado e são eleitos pela Assembleia Geral da OEA. Seus mandatos duram quatro anos e podem ser reeleitos apenas uma vez por período. Em relação às denúncias ou queixas analisadas, a Comissão não possui competência para determinar a responsabilidade de indivíduos, mas apenas quanto aos Estados integrantes da OEA. Caso seja evidenciada a violação de direitos humanos por algum Estado (seja por ação, omissão ou aquiescência), a Comissão irá elaborar um relatório que será encaminhado ao Estado denunciado, e poderá incluir recomendações como a suspenção de os atos que causam violação de direitos humanos; reparação dos danos; investigação dos responsáveis e introdução de mudanças no ordenamento jurídico do Estado. Observa-se que a possibilidade de uma solução amistosa é possível mediante diálogo e cooperação do Estado.

145 “Os Estados que reconheceram a competência da Corte IDH são: Argentina, Barbados, Bolívia, Brasil, Chile, Colômbia, Costa Rica, Equador, El Salvador, Guatemala, Haiti, Honduras, México, Nicarágua, Panamá, Paraguai, Peru, República Dominicana, Suriname, Trinidad e Tobago, Uruguai e Venezuela” (CIDH, 2010, p. 89). 
sistema interamericano, em suas sentenças e opiniões consultivas. Os casos tratados pela Corte podem ser submetidos apenas pela Comissão e pelos Estados partes, distintamente da Comissão, na qual qualquer indivíduo pode acessá-la; é justamente por meio da Comissão, com a devida observação dos trâmites previstos, que as pessoas têm acesso à Corte, de modo indireto. As situações sob jurisdição da Corte, advindas da Comissão, envolverão no processo a Comissão, o Estado e a(s) vítima(s) (CIDH, 2010, p. 8; p. 16).

Para que a Corte possa deliberar, é exigida a presença mínima de cinco juízes, sendo que as audiências, em geral, são públicas, enquanto que as deliberações dos juízes ocorrem de modo privado. Não se descarta na Corte a possibilidade de acordo diante de uma solução amistosa, podendo, então, ser encerrado o processo. Nesse caso, a própria Comissão poderá atuar como espécie de conciliadora, elaborando propostas às partes que, entrando em consenso, terão o processo finalizado pelo reconhecimento da Corte. Por outro lado, não havendo acordo, o processo segue até que seja proferida a respectiva sentença. A Corte deverá obrigatoriamente fundamentá-la e manifestar expressamente, de modo parcial ou integral, a opinião unânime dos juízes, sendo que qualquer um deles possui o direito de incluir à sentença seu voto individual, dissidente ou não. Essa sentença será definitiva e inapelável, todavia, restando questionamentos referentes ao sentido ou alcance da sentença, qualquer das partes poderá requerer à Corte uma reinterpretação, dentro de noventa dias a partir da notificação da sentença. No que tange ao cumprimento da decisão, já na Convenção Americana, os Estados signatários se comprometem a cumpri-la quando forem julgados pela Corte (OEA, 1969). Considerando que o Brasil é signatário desse sistema de proteção aos direitos humanos e não raras vezes tem despontado como violador de direitos humanos, o próximo item segue na análise específica desta conjuntura.

\section{Repercussões das decisões da Corte Interamericana de Direitos Humanos no Brasil}

Em relação à OEA, que efetivamente implementou mecanismos de proteção aos direitos humanos a partir da década de cinquenta, o Brasil não se inseriu neste sistema interamericano desde a sua origem, muito em consequência dos regimes ditatoriais vigentes no país até 1985 (VENTURA; CETRA, 2012, p. 2). Encerrada a era de governos militares no país e com a defluente (re)democratização, já na década de oitenta, o país passou a dedicar 
esforços às questões de direitos humanos, inicialmente aderindo a alguns tratados ${ }^{146}$. Mais tarde, com a Constituição Federal de 1988 já promulgada, diante de uma nova etapa jurídica e política no país, consolidando-se o processo de redemocratização, em 1992, o Brasil ratifica a Convenção Americana de Direitos Humanos (Pacto São José da Costa Rica) e, em 1998, reconhece a jurisdição obrigatória da Corte Interamericana de Direitos Humanos ${ }^{147}$.

Em análise quantitativa é possível dimensionar a situação brasileira no Sistema Interamericano, especificamente na Comissão e Corte de Direitos Humanos. Na Comissão, de acordo com informações atuais do próprio site da Comissão, o Brasil possui 31 (trinta e uma) medidas cautelares, 17 (dezessete) casos arquivados e 2 (duas) soluções amistosas, 1 (uma) no ano de 2003 e outra no ano de 2006. Atualmente, 8 (oito) condenações na Corte e 57 (cinquenta e sete) denúncias admitidas na Comissão (CIDH, 2016).

Tais condenações possuem o efeito de constituir pública e internacionalmente o Estado brasileiro como violador de direitos humanos, ignorando os inúmeros tratados e documentos internacionais que, de livre e espontânea vontade, comprometeu-se a observar. Os casos em que isso ficou determinado são: (1) Damião Ximenes Lopes - caso 12.237 de 2004; (2) Arley José Escher y Otros - caso 12.353 de 2007; (3) Sétimo Garibaldi, Brasil caso 12.478 de 2007; (4) Julia Gomes Lund y Otros (Guerrilha do Araguaia) - caso 11.552 de 2009; (5) Trabalhadores da Fazenda Brasil Verde - caso 12.066 de 2015; (6) Cosme Rosa Genoveva, Evandro de Oliveira e outros (Favela Nova Brasília) - caso 11.566 de 2015; (7) Pueblo Indígena Xucuru e seus membros - caso 12.728 de 2016; (8) Vladimir Herzog e outros - caso 12.879 de 2016.

Essas condenações tiveram impacto na realidade brasileira, em âmbito político e jurídico, motivando a criação de leis específicas, instituindo obrigações estatais e revisando diversos sistemas internos ocasionadores de violações de direitos humanos. Nesse sentido, tomam-se algumas dessas repercussões como exemplificativas dos efeitos gerados no ordenamento jurídico interno a partir de decisões do direito internacional.

A primeira condenação brasileira na Corte Interamericana ocorreu em 2006, a partir demanda da família de Damião Ximenes Lopes contra o Estado brasileiro. Damião Ximenes Lopes estava internado em instituição psiquiátrica, em Sobral, no Ceará, na qual faleceu com trinta anos de idade no ano de 1999. Seu falecimento teria sido ocasionado pela

\footnotetext{
146 "[...] foi na década de 80, que o Brasil aderiu a alguns dos principais tratados de proteção aos direitos humanos: os dois Pactos das Nações Unidas sobre direitos humanos, a Convenção contra a Tortura, a Convenção sobre os Direitos da Criança e a Convenção Interamericana para Prevenir e Punir a Tortura" (AGU, 2015).

147 "[...] o Brasil reconheceu como obrigatória a competência da CrIDH "para fatos posteriores a 10/12/1998" (data de edição do Decreto Legislativo n. 89), nos termos do Decreto n. 4463 de 08/11/2002" (VENTURA; CETRA, 2012, p. 2).
} 
contenção física sofrida por parte de funcionários da respectiva instituição, tendo recebido vários golpes enquanto estava amarrado com as mãos para trás. O laudo da necropsia revelou inúmeras lesões físicas graves que foram ignoradas pelo médico do instituto psiquiátrico no dia da morte de Damião, já que sem a realização de exame físico, recebeu alguns remédios e foi liberado. Faleceu duas horas após sua saída do hospital (RAMOS, 2006). O presente caso culminou no reconhecimento do Estado brasileiro como violador de direitos humanos por meio da sua condenação na Corte Interamericana, determinando-se que o Estado brasileiro garantisse um processo judicial célere para investigar e responsabilizar os causadores da morte de Damião; o desenvolvimento de uma política de capacitação e formação de profissionais para o tratamento de doenças mentais; o pagamento de uma indenização as familiares de Damião e a publicação da sentença no Diário oficial e em jornal de notória visibilidade.

[...] o Caso Damião Ximenes, como é conhecido no meio jurídico, abriu a possibilidade para pensarmos os direitos humanos na atenção em saúde mental e, ao mesmo tempo, se apresenta como um caso emblemático das contradições que envolvem as várias esferas envolvidas na garantia de direitos humanos no Brasil, principalmente àquelas que estão relacionadas diretamente com a proteção e cuidado de pessoas em situações vulneráveis, e denuncia as fragilidades do Estado na efetivação dos direitos fundamentais [...] (LIMA; PONTES, 2015, p.4).

A partir desta condenação (sem ignorar os esforços e movimentos anteriores por uma reforma das políticas de saúde mental no país), acentuam-se as pressões em torno da ressignificação e reconstituição dos hospitais psiquiátricos precários, sendo desativados até o ano de 2006 mais de onze mil leitos. No ano de 2001 promulgou-se a Lei 10.216/2001, que dispõe sobre a proteção e os direitos das pessoas com transtornos mentais e redireciona o modelo assistencial em saúde mental, passando a implementar-se uma nova política de proteção e atendimento às pessoas com doença mental no país. ${ }^{148}$

No tocante ao caso Escher, o Estado brasileiro foi condenado por interceptar ilegalmente ligações telefônicas de membros de associações de trabalhadores rurais ligadas ao Movimento dos Trabalhadores Rurais sem Terra, no Paraná, em 1999, tendo incorrido tanto em violações procedimentais (como autorização por autoridade incompetente, inexistência de decisão fundamentada, excesso de prazo e divulgações indevidas das gravações) quanto

\footnotetext{
148 “[...] somente após doze anos de tramitação, a Lei $n^{\circ}$ 10.216/2001 foi aprovada no Congresso Nacional, o que permite afirmar que as investigações do Caso Damião Ximenes contribuíram [sic] para acelerar o processo de aprovação da mesma, uma vez que o Brasil foi obrigado a dar resposta eminente à demanda internacional já apresentada perante a Comissão Interamericana de Direitos Humanos em 1999”. (LIMA; PONTES, 2015, p. 10).
} 
materiais (violando liberdades associativas, sigilo de comunicações, honra, vida privada e dignidade). A decisão condenatória da Corte determinou o pagamento de indenização às vítimas, a publicação da sentença em veículos de ampla circulação e a investigação dos fatos denunciados que embasaram a denúncia. Em 04 de julho de 2012, a própria Corte arquivou o caso por entender que o Brasil havia cumprido os itens aos quais foi sentenciado. Neste caso, considerando que a inviolabilidade das comunicações já é direito constitucionalmente assegurado no Brasil (art. 5 $\mathrm{XII}, \mathrm{CF} / 88$ ), a repercussão da condenação não acarretou novas proposições legislativas ou políticas públicas, mas trouxe à tona o debate sobre a importância desses direitos e destacou, de certo modo, os resquícios do legado ditatorial, em que grampos telefônicos ilegais era amplamente utilizados para monitorar opositores do regime (CEIA, 2003, p. 119-121).

No caso Sétimo Garibaldi, em que o referido trabalhador rural foi morto durante uma desocupação extrajudicial violenta de um acampamento do MST (Paraná, 1998), os desdobramentos também se restringiram ao cumprimento da sentença - o que, aliás, costuma ocorrer em grande parte dos casos.

Já em Julia Gomes Lund y Otros (caso 11.552 de 2009), em que o Brasil foi condenado pelo desaparecimento forçado de opositores da ditadura militar integrantes da Guerrilha do Araguaia na década de 1970, podem ser destacados os seguintes desdobramentos: a) aprovação da Lei n. 9.140/1995, que reconhece a responsabilidade do Estado pela morte de opositores políticos no período de 2-09-1961 a 15-08-1979; b) criação, pela mesma Lei, da Comissão Especial sobre Mortos e Desaparecidos Políticos, que visa localizar as pessoas desaparecidas, reconhecê-las como vítimas e, conforme o caso, autorizar o pagamento de indenização; c) aprovação da Lei n. 12.528/2011, que cria a Comissão Nacional da Verdade; d) aprovação da Lei 12. 527/2011, que regulamenta o acesso às informações públicas (CEIA, 2003, p. 132). Contudo, apesar das iniciativas deflagradas a partir da condenação pela Corte, importante sublinhar que o Estado brasileiro deixou de atender um ponto significativo dessa sentença, que demandaria a instauração do devido processo para investigação dos fatos e punição das responsabilidades apuradas. Aqui, também é necessário destacar o julgamento da ADPF 153 pelo Supremo Tribunal Federal, que em 2010 rejeitou o pedido da OAB pela revisão na Lei da Anistia (Lei n ${ }^{\circ}$ 6683/79).

Relativamente à condenação advinda do caso 12.066 de 2015 (Trabalhadores da Fazenda Brasil Verde), o Estado brasileiro foi responsabilizado pela violação ao direito de não ser submetido a escravidão e ao tráfico de pessoas. Na Fazenda em questão, em 15 de março de 2000 (muito embora tenha ficado demonstrado que a prática ocorreu por décadas 
naquele local), foram resgatados 85 trabalhadores cujas condições a que estiveram submetidos "ultrapassavam os elementos da servidão por dívida e de trabalho forçados, para atingir e cumprir os elementos mais estritos da definição de escravidão" (CIDH, 2016, p. 79-80). ${ }^{149}$ Para além da condenação no sentido de impor a publicização da sentença e o pagamento das indenizações fixadas, entre outras providências de praxe encontradas nas decisões da Corte, destacam-se as determinações para a adoção de medidas para impedir a prescrição e para que fossem retomadas as investigações e ações necessárias para punir os responsáveis pelos crimes cometidos.

Consequentemente, em atendimento às disposições condenatórias, em março de 2017, a Procuradoria da República do Município de Redenção (Pará) instaurou procedimento investigatório criminal para retomar a apuração, tendo sido identificadas e localizadas a grande maioria das vítimas. Dada a complexidade e gravidade dos fatos, em dezembro de 2017, foi assinada pela Procuradora-Geral da República, à época Raquel Dodge, a Portaria n. 1326, que determinou a criação de uma força-tarefa para atuar no referido procedimento investigatório (BRASIL, 2020).

Vale ressaltar que, desde o ano de 2003, já havia sido criado por meio da Portaria $\mathrm{n}^{\mathrm{o}} 1.234$ uma espécie de cadastro de empregadores que se utilizaram mão de obra escrava, conhecido como "Lista Suja do Trabalho Escravo", sendo de competência do Governo Federal publicar, atualizar e divulgar, desde então, a lista de empregadores que submetem os trabalhadores à escravidão no desenvolvimento de suas atividades e negócios.

A medida gerou divergência e polêmica, sobretudo entre os empregadores, chegando a ter sua constitucionalidade questionada, em dezembro de 2014, perante o Supremo Tribunal Federal. Nesta ocasião, o ministro Ricardo Lewandowski suspendeu a sua divulgação. Para dar continuidade à medida, a União publicou uma nova portaria interministerial (número 4, de 11 de maio de 2016), reformulando os critérios para inclusão e saída dos empregadores do Cadastro. Ao longo dos anos de 2016 e 2017, novas liminares judiciais ora suspenderam, ora autorizaram a divulgação da Lista Suja (BRASIL, MPT, 2020),

\footnotetext{
149 "Nesse sentido, a Corte constata que: i) os trabalhadores se encontravam submetidos ao efetivo controle dos gatos, gerentes, guardas armados da fazenda, e, em última análise, também de seu proprietário; ii) de forma tal que sua autonomia e liberdade individuais estavam restringidas; iii) sem seu livre consentimento; iv) através de ameaças, violência física e psicológica, v) para explorar seu trabalho forçado em condições desumanas. Além disso, as circunstâncias da fuga realizada pelos senhores Antônio Francisco da Silva e Gonçalo Luiz Furtado e os riscos enfrentados até denunciarem o ocorrido à Polícia Federal demonstram: vi) a vulnerabilidade dos trabalhadores e vii) o ambiente de coação existente nesta fazenda, os quais viii) não lhes permitiam alterar sua situação e recuperar sua liberdade. Por todo o exposto, a Corte conclui que a circunstância verificada na Fazenda Brasil Verde em março de 2000 representava uma situação de escravidão" (CIDH, 2016, p.79-80).
} 
a qual, a despeito das contestações, é considerada um importante mecanismo em favor da transparência e do combate ao trabalho escravo.

Também foi em 2015 que a Comissão Interamericana de Direitos Humanos submeteu à Corte Interamericana de Direitos Humanos o caso Favela Nova Brasília (Cosme Rosa Genoveva, Evandro de Oliveira e outros - caso 11.566 de 2015), no qual se acusava o Estado brasileiro de violação de direitos humanos pelas falhas e pela demora na investigação e punição dos responsáveis pelas execuções extrajudiciais de 26 pessoas que teriam ocorrido no âmbito de incursões policiais realizadas pela Polícia Civil do Rio de Janeiro em 18 de outubro de 1994 e em 8 de maio de 1995 na Favela Nova Brasília. A acusação também compreendia atos de tortura e violência sexual cometidos por parte de agentes policiais contra três mulheres, sendo duas adolescentes (CIDH, 2017).

$\mathrm{Na}$ sentença condenatória advierem disposições no sentido de determinar que o Estado brasileiro: a) conduzisse investigação de modo eficaz, diligente e em prazo razoável sobre os fatos relacionados às mortes e à violência sexual, visando identificar, processar e, sendo pertinente, punir os responsáveis; b) oferecesse gratuitamente tratamento psicológico e psiquiátrico às vítimas; c) publicasse a sentença; d) realizasse um ato público de reconhecimento de sua responsabilidade internacional com relação aos fatos; e) publicasse relatório anual com dados relativos às mortes ocasionadas durante operações da política em todos os estados da federação; f) estabelecesse os mecanismos normativos necessários para que, em casos de futuras ocorrências semelhantes à relatada, a investigação fosse conduzida por um órgão independente da força pública envolvida; g) adotasse medidas necessárias para que o Estado do Rio de Janeiro reduza a letalidade e a violência policiais; h) implementasse um programa permanente e obrigatório sobre atendimento a mulheres vítimas de estupro destinado a todos os níveis das polícias; i) pagasse as indenizações fixadas a título de dano imaterial; j) restituísse ao Fundo de Assistência Jurídica às Vítimas (CIDH) a quantia desembolsada durante a tramitação do caso (CIDH, 2017, p. 89-90).

Embora se reconheça a complexidade de algumas medidas, neste caso, houve uma excessiva demora na adoção de providências, mesmo as mais simples de serem atendidas, tanto que, um ano após a sentença, data limite fixada para o seu cumprimento, inclusive, nada havia sido feito (RIBEIRO; OLIVEIRA; SIQUEIRA, 2017). Foi apenas em dezembro de 2019 que se teve notícia da denúncia pelo Ministério Público do Rio de Janeiro contra dois policias envolvidos no caso em 1994.

Em outro contexto, no ano de 2016, foi submetido à Corte o caso Pueblo Indígena Xucuru e seus membros contra a República Federativa do Brasil (caso 12.728 de 2016), no 
qual se denunciou a violação do direito à propriedade coletiva e à integridade pessoal do Povo Indígena Xucuru, dada a demora de mais de 16 anos (entre 1989 e 2005) no processo administrativo de reconhecimento, titulação, demarcação e delimitação de suas terras e territórios ancestrais, bem como da demora na tomada de providências para que o referido povo indígena pudesse exercer pacificamente esse direito. Além disso, as acusações também compreendiam o descumprimento do prazo razoável no respectivo processo administrativo (CIDH, 2018).

$\mathrm{Na}$ sentença, para além das previsões comumente presentes nas condenações da Corte, foi determinado que o Estado brasileiro deveria garantir, de maneira efetiva e imediata, o direito de propriedade coletiva do Povo Indígena Xucuru sobre seu território, bem como remover quaisquer obstáculos ao exercício desse direito, além do pagamento de indenização (CIDH, 2018). Em fevereiro de 2020, a indenização, no montante de um milhão de dólares, foi depositada pelo Estado brasileiro na conta da Associação Xucuru, sendo que o valor constituirá um Fundo de Desenvolvimento Comunitário para os povos afetados. Contudo, ainda restam algumas indenizações a serem pagas, e o processo de desintrusão do território de modo a garantir o seu pleno e efetivo exercício pelo povo Xucuru ainda não foi concluído (CONSELHO INDIGENISTA MISSIONÁRIO, 2020).

Por fim, na condenação mais recente do Estado brasileiro, o caso Vladimir Herzog e outros (caso 12.879 de 2016) retoma o que certamente foi um dos períodos mais dolorosos da história nacional, já que o caso submetido à Corte dizia respeito ao assassinato do jornalista Vladimir Herzog nos porões da ditadura brasileira.

$\mathrm{Na}$ descrição que se extrai da própria abertura da decisão da Corte, o caso se refere à responsabilidade internacional do Estado pela situação de impunidade diante da detenção arbitrária, da tortura e da morte do jornalista Vladimir Herzog. Tais fatos ocorreram em 25 de outubro de 1975, durante a ditadura militar. Dentre outros fatores apontados para esse quadro de impunidade, destaca-se a Lei n. 6.683/79 (Lei de Anistia, que proíbe a investigação e punição dos crimes cometidos no período ditatorial), promulgada durante a ditadura militar brasileira (CIDH, 2018) e declarada constitucional pelo Supremo Tribunal Federal em 2010, na ocasião do julgamento da Arguição de Descumprimento de Preceito Fundamental n. 153.

A condenação impôs ao Estado brasileiro os deveres de: a) reiniciar a investigação e o respectivo processo penal para identificar e, sendo pertinente, punir os responsáveis pela tortura e morte de Vladimir Herzog, ao qual foi atribuído o caráter de crime contra a humanidade; b) adotar as medidas necessárias para o reconhecimento da imprescritibilidade 
dos crimes contra a humanidade; c) realizar ato público de reconhecimento da responsabilidade internacional perante os fatos em relação aos quais se deu a condenação; d) publicar e publicizar a sentença; e) pagar as indenizações fixadas a título de danos materiais e imateriais; f) reembolsar o Fundo de Assistência Jurídica a Vítimas da Corte (CIDH, 2018).

Dentre as consequências da condenação, destaca-se que o oferecimento de denúncia pelo Ministério Público Federal no dia 17 de março de 2020 contra seis pessoas envolvidas no assassinato de Vladimir Herzog e na elaboração do falso laudo que atestou o seu "suicídio". Caso a denúncia seja recebida, os acusados responderão por homicídio por motivo torpe com emprego de tortura, além de omitir ou inserir informações falsas em documentos públicos. Em face da Lei de Anistia, contudo, ainda restam dúvidas se a investigação e eventual punição dos responsáveis irá se concretizar (ANGELO, 2020).

Enfim, a presente análise, ainda que breve, dados os limites impostos pela natureza do trabalho em questão, permite identificar um padrão quanto ao modo de cumprimento das condenações: a limitação às determinações mais básicas das sentenças, normalmente associadas à indenização às vítimas, publicização da condenação e investigações dos fatos. De fato, inexiste um caminho institucional interno para densificar o conteúdo das obrigações impostas nas sentenças condenatórias, o que seria decisivo para este fim. Quanto às medidas cuja efetividade dependeria da formulação de políticas públicas, por exemplo, as dificuldades começam desde a "articulação entre órgãos que diferem tanto no que diz respeito a suas competências quanto em sua organização e estrutura" e em relação aos quais não há um percurso definido para tanto. Mesmo quando há estrutura jurídica prevista pelo ordenamento jurídico interno, dificuldades institucionais clássicas como "um aparato policial e investigativo pouco eficiente, bem como um Judiciário moroso e uma formação deficitária dos agentes estatais em direitos humanos" também contribuem para o descumprimento das determinações internacionais (COIMBRA, 2004, p. 71).

\section{Conclusão}

O trabalho propôs-se a investigar o sistema interamericano de proteção aos direitos humanos e as condenações sofridas pelo Estado brasileiro, visando identificar as repercussões concretas no ordenamento jurídico interno a partir das condenações internacionais por violação de direitos sofridas pelo Brasil.

Para isso, iniciou-se pela própria justificativa da existência dos sistemas protetivos regionais, alinhada a uma perspectiva crítica dos direitos humanos, cuja pretensa 
universalidade não pode atropelar as diferenças sócio-político-culturais das diferentes nações, sob pena de tornar-se hegemônica e até mesmo opressora.

Após, foi reconstruído brevemente o percurso histórico de formação do sistema interamericano, dada a pertinência com o objetivo proposto de avaliar o contexto e as respectivas condenações sofridas pelo Estado brasileiro no âmbito deste sistema.

Por fim, concluiu-se que, apesar de o Brasil ter acatado as condenações e empenhado esforços no cumprimento de boa parte de suas determinações, há entraves institucionais que ainda dificultam a plena efetividade das medidas constantes das sentenças da Corte Interamericana de Direitos Humanos. Dessas sentenças, de fato, constatam-se decorrentes medidas legislativas e políticas públicas que confirmam a influência das decisões internacionais no direito interno. Contudo, considerando-se a extrema relevância dos temas em questão, tais medidas de internalização ainda estão longe de alcançarem um padrão satisfatório de respeito aos direitos humanos.

\section{Referências}

AGU. Advocacia-Geral da União. Sistema Interamericano de Direitos Humanos. 2015. Disponível em: <http://www.agu.gov.br/page/content/detail/id_conteudo/113927>. Acesso em: 20 jun. 2019.

ANGELO, Tiago. MPF denuncia seis pessoas por assassinato de jornalista Vladimir Herzog. Revista Consultor Jurídico. Disponível em: <https://www.conjur.com.br/2020-mar-17/mpfdenuncia-seis-pessoas-assassinato-vladimir-herzog>. Acesso em: 11 abr. 2020.

BRASIL. Ministério Público Federal - Caso Fazenda Brasil Verde. Disponível em: $<$ http://www.mpf.mp.br/pgr/documentos/entenda-o-caso-_fazenda-brasil-verde.pdf $>$. Acesso em: 09 abr. 2020.

BRASIL. Ministério Público do Trabalho. Disponível em: <https://mpt.mp.br/>. Acesso em: 09 abr. 2020.

CEIA, Eleonora Mesquita. A jurisprudência da Corte Interamericana de Direitos Humanos e o desenvolvimento da proteção dos direitos humanos no Brasil. Revista EMERJ, Rio de Janeiro, v. 16, n. 61, p. 113-152, jan.-fev.-marc. 2003. Disponível em:

$<$ http://www.emerj.tjrj.jus.br/revistaemerj>. Acesso em: 22 Jun. 2019.

CHAUÍ, Marilena. O que é ideologia. São Paulo: Brasiliense, 2012.

CIDH. Comissão Interamericana de Direitos Humanos. Informes de arquivo. 2016.

Disponível em: < http://www.oas.org/pt/cidh/decisiones/archivos.asp>. Acesso em: 19 jun.

2019. 
CIDH. Comissão Interamericana de Direitos Humanos. Casos na Corte. 2016. Disponível em: $<$ http://

www.oas.org/pt/cidh/decisiones/demandas.asp>. Acesso em: 20 jun. 2019.

CIDH. Comissão Interamericana de Direitos Humanos. Medidas Cautelares. 2016.

Disponível em: <http://www.oas.org/es/cidh/decisiones/cautelares.asp>. Acesso em: 20 jun. 2019.

CIDH. Comissão Interamericana de Direitos Humanos. Sistema de Petições e Casos Folheto Informativo. 2010.Disponível em:

$<$ http://www.oas.org/es/cidh/docs/folleto/CIDHFolleto_port.pdf $>$. Acesso em: 19 jun. 2019.

CIDH. Comissão Interamericana de Direitos Humanos. Soluciones Amistosas. 2016.

Disponível em: $<$ http://www.oas.org/es/cidh/decisiones/amistosas.asp >. Acesso em: 19 jun. 2019.

CIDH. Comissão Interamericana de Direitos Humanos. Caso Trabalhadores da Fazenda Brasil Verde vs. Brasil - Sentença de 20 de outubro de 2016. Disponível em:

$<$ http://www.oas.org/pt/cidh/decisiones/demandas.asp>. Acesso em: 09 abr. 2020.

CIDH. Comissão Interamericana de Direitos Humanos. Caso Favela Nova Brasília vs. Brasil - Sentença de 16 de fevereiro de 2017. Disponível em:

$<$ http://www.corteidh.or.cr/docs/casos/articulos/seriec_333_por.pdf $>$. Acesso em: 09 abr. 2020 .

CIDH. Comissão Interamericana de Direitos Humanos. Caso do Povo Indígena Xucuru e seus membros vs. Brasil - Sentença de 05 de fevereiro de 2018. Disponível em:

$<$ http://www.corteidh.or.cr>. Acesso em: 09 abr. 2020.

CIDH. Comissão Interamericana de Direitos Humanos. Caso Herzog e outros vs. Brasil Sentença de 15 de março de 2018. Disponível em: <http://www.corteidh.or.cr>. Acesso em: 09 abr. 2020.

COIMBRA, Elisa Mara. Sistema Interamericano de Direitos Humanos: desafios à implementação das decisões da Corte no Brasil. SUR, Revista Internacional de Direitos Humanos. v. 1, n.1, jan. 2004, São Paulo. Disponível em: $<$ https://sur.conectas.org/wpcontent/uploads/2017/11/sur19-port-elisa-mara-coimbra.pdf $>$. Acesso em: 22 Jun. 2019.

COELHO, Luiz Fernando. Teoria crítica do direito. 3. ed. Belo Horizonte: Del Rey, 2003.

CONSELHO INDIGENISTA MISSIONÁRIO. Povo Xukuru recebe indenização do governo após sentença da CIDH que condenou o Estado por violações de direitos humanos.

Disponível em: $<$ https://cimi.org.br/2020/02/povo-xukuru-recebe-indenizacao-do-governofederal-como-sentenca-da-cidh-que-condenou-o-estado-por-violacoes-de-direitos-humanos/>. Acesso em 11 abr. 2020.

GALLARDO, Helio. Novos pressupostos para a temática de direitos humanos. In: RÚBIO, David Sánches; FLORES, Joaquín Herrera; CARVALHO, Salo de (Orgs). Derechos Discriminados y Olvidados. 2. ed. Porto Alegre: EDIPUCRS, 2010, p. 55-71. 
GALLARDO, Helio. Teoria crítica: matriz e possibilidade de direitos humanos. 1. ed. Tradução de Patricia Fernandes. São Paulo: Editora Unesp, 2014.

HERRERA FLORES, Joaquín. Teoria crítica dos direitos humanos. Os direitos humanos como produtos culturais. Versão ebook. Rio de Janeiro: Lumen Juris, 2009.

OEA. Organização dos Estados Americanos. Convenção Americana de Direitos Humanos. San José, 1969. Disponível em: $<$ https://www.cidh.oas.org/basicos/ portugues/c.convencao_americana.htm>. Acesso em: 20 jun. 2019.

OLIVEIRA, Adriana Ferreira Serafim de. A tutela dos direitos fundamentais dos povos islâmicos no sistema regional árabe de proteção dos direitos humanos. In: MARTINS, Rui Decio; BIZAWU, Sébastien Kiwonghi (Orgs.), Direito internacional dos direitos humanos I - Conpedi. Florianópolis: CONPEDI, 2016. Disponível em:

$<$ http://www.conpedi.org.br/publicacoes>. Acesso em: 20 jun. 2019, p. 29-46.

PRONER, Carol. Direitos humanos e seus paradoxos: análise do sistema interamericano de proteção. Porto Alegre: Sergio Antonio Fabris, 2002.

RAMOS, André de Carvalho. Reflexões sobre as vistorias do Caso Damião Ximenes Lopes. Conjur. 2006. Disponível em: <https://www.conjur.com.br>. Acesso em: 07 jun. 2019.

RIBEIRO, Raisa Duarte da Silva; OLIVEIRA, Geziel Viana de; SIQUEIRA, Isadora de Sousa. Núcleo Interamericano de Direitos Humanos da Faculdade Nacional de Direito da UFRJ. Disponível em: < https://nidh.com.br/cosme-rosa-genoveva-e-outros-vs-brasil-2017os-homicidios-na-favela-nova-brasilia-e-dever-de-reformulacao-da-pratica-policial/ > . Acesso em: 10 abr. 2020.

SÁNCHEZ RUBIO, David. Encantos e desencantos dos direitos humanos: de emancipações, libertações e dominações. Tradução de Ivone Fernandes Morcilho Lixa e Helena Henkin. Porto Alegre: Livraria do Advogado, 2014.

SANTOS, Boaventura de Souza; CHAUÍ, Marilena. Direitos humanos, democracia e desenvolvimento. São Paulo: Cortez, 2013.

VENTURA, Deisy; CETRA, Raísa Ortiz. O Brasil no Sistema Interamericano de Direitos Humanos: de Maria da Penha a Belo Monte. In: Seminário Internacional Limites e Possibilidades da Justiça de Transição? Impunidade, direitos e democracia, 2012, Porto Alegre. Disponível em: <http://www.conectas.org>. Acesso em: 20 jun. 2019.

Data de recebimento: 03.06 .2020

Data de aprovação: 08.08.2020 